\title{
Second-order Mental State Attribution in Children with Intellectual Disability: Cognitive Functioning and Some Educational Planning Challenges
}

\author{
Anastasia Alevriadou (Corresponding author) \\ Associate Professor of Special Education \\ Department of Preschool Education \& Department of Early Childhood Education \\ School of Education, University of Western Macedonia Greece \\ 3rd klm. National Road Florina-Niki, 53100, Florina, Greece \\ E-mail: alevriadou@uowm.gr \\ Stergiani Giaouri ph.D. \\ Research Assistant \\ Department of Preschool Education \& Department of Early Childhood Education \\ School of Education, University of Western Macedonia Greece \\ 3rd klm. National Road Florina-Niki, 53100, Florina Greece \\ E-mail: stellagiaouri@gmail.com
}

Received: September 9, 2011

Accepted: November 10, 2011

Published: December 30, 2011

doi:10.5539/jedp.v1n1p146

URL: http://dx.doi.org/10.5539/jedp.v1n1p146

\begin{abstract}
Second-order mental state attribution in two groups of children with non-specific intellectual disability and Down syndrome was investigated. The children were compared to overall mental age-matched group of typically developing children. The aim of the present study was to determine the specificity of the theory of mind deficit to different groups of children with intellectual disability. The results clearly showed that children with Down syndrome performed more poorly than the children with non-specific intellectual disability, and that typically developing children perform significantly better than do other groups. The findings are discussed in terms of the specificity of the etiology-related profiles of intellectually disabled groups. Several critical issues related to intervention strategies in the field of intellectual disability are also discussed, considering the educational practices.
\end{abstract}

Keywords: Down syndrome, Educational practices, Intellectual disability, Theory of mind

\section{Introduction}

Intellectual disability (ID) is invariably associated with impairments in social behavior that are manifested across a range of contexts and tasks. Children and young people with ID have social difficulties (Margalit, 1995), especially in spontaneous manifestation of behaviors and communication skills, emotional responses and social perception associated with effective psychosocial functioning and adaptation within the structure of community (Gottlieb \& Leyser, 1981). It has been described that people with ID experience high levels of loneliness, social anxiety and lack of satisfaction with their social interactions (Williams \& Asher, 1992). In addition, children with ID exhibit inappropriate problem solving patterns during conflicts with peers, are less accepted as reflected by both peer socio-metric and behavioral measures, have more difficulties forming in-depth relationships with peers as indicated by more limited linkages between peers across school and community settings, and have fewer reciprocal friendships (Gresham, Elliott, \& Black, 1987. Guralnick et al., 1998, 2006). Kavale and Forness (1996) from a meta-analysis of 152 studies calculated that $75 \%$ of the people with ID studied experienced social difficulties. Related studies of school-age children reveal that these patterns persist over time, often leading to social isolation (Howell, Hauser-Cram, \& Warfield, 2001). 
An especially important system that may be a source of difficulty for individuals with ID is their theory of mind (ToM). Theory of mind refers to the ability to attribute mental states (e.g., beliefs, desires, emotions, and intentions) to the self and to others (Astington, 1993). In addition, ToM is a dimension of social cognition, and it is the foundation for performance in a number of important social tasks, including meeting the informational needs of one's listener (Frith, 1996), creating a coherent and comprehensible narrative (Astington, 1994), soliciting confirmation of one's interpretation of another person's sentences (Abbeduto et al., 1998) and reacting to emotional distress in others (Tager-Flusberg \& Sullivan, 1994).

Previous research with etiologically heterogeneous groups of persons with ID has shown ToM to be substantially delayed or impaired (Benson et al., 1993; Tager-Flusberg \& Sullivan, 1994). More recently, researchers in the field of ID have begun to explore the possibility that ToM is differentially impaired across different genetic syndromes, including Down syndrome (DS), fragile X syndrome and Williams syndrome (Abbeduto et al., 2004; Mazzocco et al., 1993; Yirmiya et al., 1998). DS, however, has been studied less frequently with respect to ToM.

Specifically, individuals with DS are known to have high empathic abilities and better social skills compared to other individuals with ID (Beeghly et al., 1990; Kasari et al., 1990). Furthermore, they are generally perceived by others as cheerful and lovable (Dykens et al., 2000). Most developmental psycholinguists also consider the uses of language in socially relevant ways, or the pragmatics of children with DS as more tied to overall cognitive levels and less impaired than functioning in other areas of language (Rondal, 1996).

However, despite their sociability, children and adolescents with DS experience difficulty with their peers (Dykens et al., 2002). Furthermore, the maladaptive behavior of children with DS more adversely affected their social relationships than other recreational activities (Hodapp \& Zigler, 1990). The stereotype of people with DS as happy, placid individuals with a gift for mimicry is not borne out by recent behavioral research. "Stubbornness" and obsessional features seem to be over-represented, and many people with DS react adversely in situations involving conflict. Thus, the apparent contradiction between their interests in others coupled with their social difficulty suggests that social cognition, or ToM, may not be an area of strength for these individuals.

Much of the research about ToM ability relies on false belief tasks as indicators of whether or not a child has mental state understanding (Lewis et al., 2006). The aim of such tasks is to assess the ability of the participant to reason about another person's beliefs when those beliefs are different from his or her own. There have been hundreds of articles concerning these tasks, comparing the performance of different groups, of the same mental age (MA) or chronological age (CA), exploring how success correlates with linguistic and general cognitive and social skills, and extending the task in various ways (Abbeduto et al., 2001; Tager-Flusberg \& Sullivan, 1994; Yirmiya et al., 1998). To date, only a few investigators have explored ToM abilities in children with DS (Cornish et al., 2005; Zelazo et al., 1996). While Baron-Cohen et al. (1985) found that $85 \%$ of a group of children with DS could pass a standard first-order false belief task of ToM, Charman and Campbell (1997) reported that $39 \%$ of a sample of children with DS passes false belief tasks. Abbeduto et al. (2001) found that the participants with DS, as a group, answered substantially fewer false beliefs questions correctly than did typically developing (TD) participants.

Another, perhaps even more socially relevant achievement in the development of a ToM, is the ability to attribute second-order or embedded mental states (e.g., he thinks that she thinks). Being able to represent what one person thinks about what a second person thinks allows us to understand not only another's belief about the world (a first-order belief) but also to understand that person's concern about yet another person's belief about the world (a second-order belief) (Sullivan \&Tager-Flusberg, 1999). Second-order tests can be another way of revealing if there is a specific developmental delay in theory of mind at a later point in development. Early studies of TD children showed that an understanding of second-order mental states emerges between the ages of 5 to 7 (Hogrefe, 1986; Leekam, 1991; Perner \& Howes, 1992).

Second-order reasoning by individuals with DS has not been investigated directly. Furthermore, Hogrefe (1986), Leekam (1991), and Perner \& Howes (1992), using a simpler second-order task that substantially reduced the information-processing demands of the task, found that $58 \%$ of participants with autism and $67 \%$ of participants with ID between 8 and 22 years of age were able to attribute second-order beliefs. Using the Sullivan et al. (1994) procedure, Karmiloff-Smith et al. (1995) found that 7 out of 8 individuals with Williams syndrome (88\%), ranging in age from 9 to 23 years, were able to attribute second-order mental states.

Thus, our goal in the present study was to explore second-order reasoning in a group of children with DS. We compared the performance of children with DS to two other groups: children with non-specific ID and TD children. The three groups were matched on overall MA as measured by WISC-III GR test (Georgas et al., 1997). All previous ToM research aimed to test the hypothesis of delay versus the "difference" hypothesis about the 
ToM belief development in atypical populations in comparison with TD populations. The similar-structure hypothesis (Zigler, 1969), which is tested in this study, proposes that people with ID develop in line with their MA, therefore, there aren't any statistical significant differences in their performance when compared to those without ID, matched on MA. When matched on overall MA to children of average intelligence, persons with ID but with no organic damage should show no particular areas of strengths or weaknesses. Actually, this is the idea that persons with ID proceed, in order, through the usual sequences of development. Research studies (Hodapp, Burack, \& Zigler, 1990) showed that persons with ID develop more slowly but in the same order as do persons without ID. The "difference" approach claims that ID persons are qualitatively different from non ID persons and it also hypothesizes that children with ID suffer from one or another specific defect causing their disability, although they do not agree about the nature of the specific cause. For example, ID has been attributed to deficits in attention, strategy use, cognitive rigidity, or deficiencies in logical analysis and conceptual ability (MacLean, 1997).

Therefore, three questions were investigated in the present study: (a) "Do children with ID (non-specific ID and DS) differ in their performance on the second-order false beliefs tasks when compared with TD children matched on their MA?", (b) "Do children with ID (non-specific ID and DS) have similar or different strengths and weaknesses in these ToM tasks?", and (c) "Which verbal and performance abilities, as assessed with the WISC-III, are associated with performance on the ToM tasks for each one of the groups?"

\section{Method}

\subsection{Participants}

The present study involved two clinical groups of participants: 23 children with DS and 41 children with non-specific ID. The control group consisted of $42 \mathrm{TD}$ children. The sex ratio in these three groups was approximately 1:1 (M:F). The mean CA in DS group $(M=10,18$ years, $S . D .=0,46)$ and the mean CA in non-specific ID group $(M=9,77$ years, $S . D .=0,49)$ were significantly higher than in the TD group $(M=6,49$ years, $S . D .=0,33), F_{(2,103)}=812, p<.001$. The groups were matched on overall MA using the WISC-III-GR (Georgas et al., 1997). The mean MA did not differ among the ID groups [(DS group: $M=6,60$ years, $S . D .=0,38$ ), (ID group: $M=6,83$ years, $S . D .=0,60)]$ and the TD group $(M=6,83$ years, $S . D .=0,41), F_{(2,103)}=1,98, p=.14, \mathrm{p}>.10$. The participants were native speakers of Greek origin. All children with ID had mild intellectual disability (IQ: 55-70) (Luckasson et al., 2002) and were receiving special education and none were living in institutional settings. Furthermore, none of the children in any of the groups had sensory impairments including hearing deficits and decreased visual acuity. Finally, none of the children were on drugs.

\subsection{Procedure}

Five second-order false belief stories were distributed in order to estimate the understanding of the mental state "belief": three stories of the location change and two stories of the unexpected-content. The stories were presented in counterbalanced order and were accompanied by three or four colored scenes on $\mathrm{H} / \mathrm{Y}$ display, depicting the characters and the main story events. All participants were tested individually at their school in two 60 min sessions. In the first session, participants received the WISC-III. Then they received the ToM stories. The scores in the result section are out of 5 .

\subsubsection{Location Change Task}

The procedure for the location change false belief task was consistent with that utilized by Perner and Wimmer (1985). This is the first story presented. Each child was introduced to two protagonists Nick and John, who were playing in the playground. John saw the canteen and he was very hungry, but he had no money to buy a sandwich, so he went to home to get money. The other boy Nick approached the canteen and the owner said that he will leave the playground and go to school. On the way to home, John met with the canteen's owner, and said him that he would go to school. After a while, Nick came to John's house and the experimenter asked the child a series of questions: The second-order false belief question: "Where Nick thinks that John will look for the canteen?" The memory question: "Where was the canteen in the beginning?" And the reality question: "Where is the canteen really?" A similar procedure was followed for the remaining tasks. A child scored one point for the belief question. Participants were counted as having passed if they answered the memory, reality, and prediction questions correctly.

\subsubsection{Unexpected Content Task}

The procedure for the unexpected content false belief task was consistent with that utilized by Gopnick and Astington (1988).This is the first story presented. Each child was introduced to two protagonists Ann and Mary who saw a chocolate box on a table. The box was closed. Then Mary left the room and Ann opened the box and 
was then shown that the box contained something different (e.g., money). Surprisingly, Mary was hidden behind the door to see what was inside the box and then came into the room. The experimenter asked the child a series of questions: The second-order false belief question: "What Ann thinks that Mary thinks about what's inside the box?" The memory question: "What Mary said when saw the box closed in the beginning?" And the reality question: "What's really in this box?" A similar procedure was followed for the remaining tasks. A child scored one point for the belief question. In order to pass each trial, the participant had to answer the belief question and both control questions correctly.

\section{Results}

A one-way ANOVA with group as the between-subjects variable was used to examine performance on the second-order false belief tasks. This analysis indicated that factor group was significantly influenced children's performance on the second-order false belief tasks $[\mathrm{F}(2,103)=72,49 \mathrm{p}<.05]$. On the false belief question, significantly more of the TD children passed than did the children with ID and DS. A Post hoc LSD test indicated that there was statistically significant difference in ID vs DS groups $(p<.05)$ and TD vs ID $(p<.05)$ on the tasks' performance. The effect of sex and the interaction of group and question type (second-order belief) were not significant. Table 1 presents descriptive statistics for each group and tasks.

Moreover statistical analysis indicated that there were positive and significant Pearson correlations between the second-order false belief tasks and WISC-III. Actually, for the ID group Performance Intelligence Quotient $(\mathrm{r}=$ $0.55, \mathrm{p}<.01)$, Full Scale Intelligence Quotient $(\mathrm{r}=0.63, \mathrm{p}<.01)$, Code $(\mathrm{r}=0.52, \mathrm{p}<.01)$, and Block Design $(\mathrm{r}=$ $0.57, \mathrm{p}<.01)$ were significantly correlated with the performance on the tasks. For the DS group Performance Intelligence Quotient was significantly correlated with the performance on the tasks $(r=0.51, \mathrm{p}<.05)$. Finally, there were not significant Pearson correlations between the second-order false belief tasks and CA or overall MA for each group.

\section{Discussion}

The main finding in this study was that the children with DS performed worse than MA-matched children with non-specific ID and TD in attributing second-order mental states. For participants in the two ID groups, the second-order belief was significantly more difficult than in the TD group. This relative ease of the TD children is consistent with previous findings using this similar method with typically developing 4 to 6 year olds (Sullivan et al., 1994) and clinical populations (Hogrefe, 1986; Leekam, 1990; Perner \& Howes, 1992). Whereas first-order tests correspond to a 4 year old mental age level, second-order tests correspond to a 6 year old mental age level.

All two groups of children with ID and DS who participated in the present study performed worse than did much younger TD children, despite the same MA. Our results were not in accordance with the developmental approach of similar structure hypothesis at least for TD and non-specific ID children. It has also been concluded that a modified version of the existing theories of the developmental approach and the "difference" approach is needed to intelligibly account for the conflicting data of the performance of children with ID on ToM tasks.

However, the key finding from the present study was the difference between the two ID groups on the false belief tasks. This cross ID dissociation in ToM abilities underlines the importance of looking beyond global outcomes of cognitive and behavior functioning and the necessity to move towards isolating those subtle differences in information processing that point to DS specific developmental trajectories (Nadel, 2006). Therefore, the specific characteristics and the etiology of any given comparison group of ID may relate to the results and the interpretation of any study. Then, it is possible to say on the basis of the present study that theory of mind deficits can be explained by the specific cognitive phenotype of ID (for example DS) rather than their overall ability. This poorer performance needs to be explored further because it suggests that other factors may influence higher order social reasoning, as measured in these ToM tasks. Performance on second-order false belief tasks requires: linguistic abilities and, some executive functions-including working memory, inhibitory control and attention to the sequence of events in these stories (Sullivan \&Tager-Flusberg, 1999), which are generally deficient in the atypical population. Another possibility is that our use of pictures to support the narrative may have diverted the attention of the children with ID and DS, who perhaps find it more difficult to listen to stories with such distractions, although they were motivated with these tasks.

Additionally, examining the correlations of false belief performance in the groups, we found that only for the clinical groups, the false belief tasks tended to correlate with cognitive-performance abilities, as measured by the WISC-III, such as Code and Block Design. Indeed, these performance subscales require executive function, visual short-term memory skills and problem solving styles, which closely resemble the sequencing of these ToM tasks. The notion that false belief tasks require information processing and performance abilities(e.g., 
working memory, rule-based reasoning, executive abilities) besides an intact theory of mind has support from other work (Frye et al., 1995; Gordon \& Olson, 1998; Hughes, 1998) however, it is not clear in relation to individuals with ID in which domain any particular impairments might lay.

Furthermore, the study of specific profiles of development among various etiological groups of children with ID is essential for all aspects of research and intervention in the field of ID (Cicchetti \& Beeghly, 1990; Dykens, 1998; Hodapp, Burack, \& Zigler, 1990). The systematic comparison of theory of mind abilities in individuals with ID with differing etiologies is an important goal for future work, especially as it is clear that specific organic syndromes do have specific behavioral and neuropsychological profiles (Pennington \& Ozonoff, 1996; Simonoff et al., 1996). Such a finding would have extensive implications for the ways trainers could interact with groups of ID to develop ToM understanding and empower them to use this type of thinking in their everyday lives. Establishing appropriate and effective interactions with peers constitutes a major concern for a substantial majority of young children with ID. Early patterns of fragile, often negative, relationships with peers place these young children on a developmental trajectory destined to create long-term interpersonal problems and to diminish their quality of life (Guralnick et al., 2006).

The findings from our study indicate that children with ID and DS have difficulty with second-order reasoning, particularly understanding that one person may hold a false belief about what a second person knows about a situation. It is, thus, not surprising that children with ID, including highly sociable children with DS, have difficulty with social relationships in middle childhood and adolescence. These kinds of deficits in social understanding have important consequences for their ability to interpret the kinds of complex everyday behaviors, such as speaking and listening in real social situations at home, at school, and in the community (Sullivan \&Tager-Flusberg, 1999). An understanding of mental states, which are especially important in social interactions, is acquired in part through experiences with more knowledgeable members of the culture (Dunn, 1994). As children and adolescents with ID get older, they often have more social opportunities and have more contacts within the community. Within the context of peer relationships, adolescents practice and refine social skills; access support systems, shared activities, and companionship and learn peer norms and values (Hartup, 1999). Through such experiences, they are likely to develop a more advanced understanding of mind, including the ability to attribute second-order beliefs.

\section{Conclusion}

Finally, etiology-based research is important for more specific, targeted educational interventions. As noted earlier, children with ID show etiology-related patterns of cognitive and learning strengths and weaknesses. Giving, finally, attention to individual differences in children with ID of different etiology, teachers can design more effective skill and support-based intervention practices and inclusive conditions, by using flexible educational strategies. Specifically, interaction with general education peers may play a role in academic, functional, and social skill development, as well as contribute to increased social competence, attainment of educational goals, friendship development, and enhanced quality of life.

\section{References}

Abbeduto, L., Pavetto, M., Kesin, E., Weissman, M., Karadottir, S, O’Brien, A., \& Cawthon, S. (2001). The linguistic and cognitive profile of Down syndrome: Evidence from a comparison with fragile $\mathrm{X}$ syndrome. Down syndrome Research and Practice, 7(1), 9-15.

Abbeduto, L., Short-Meyerson, K., Benson, G., \& Dolish, J. (2004). Relationship between theory of mind and language ability in children and adolescents with intellectual disability. Journal of Intellectual Disability Research, 48, 150-159. http://dx.doi.org/10.1111/j.1365-2788.2004.00524.x

Abbeduto, L., Short-Meyerson, K., Benson, G., Dolish, J., \& Weissman, M. (1998). Understanding referential expressions: Use of common ground by children and adolescents with mental retardation. Journal of Speech, Language, and Hearing Research, 41, 348-362.

Astington, J. (1993). The Child's Discovery of the Mind. Cambridge, MA: Harvard University Press.

Astington, J. (1994). Children's developing notions of other's minds. In J. Duchan, L. Hewitt \& R. Sonnenmeier (Eds.), Pragmatics: From theory to practice (pp. 72-87). Englewood Cliffs, NJ: Prentice Hall.

Baron-Cohen, S., Leslie, A., \& Frith, U. (1985). Does the autistic child have a 'theory of mind'? Cognition, 21, $37-46$.

Beeghly, M., Weiss-Perry, B., \& Cicchetti, D. (1990). Beyond sensorimotor functioning: Early communicative and play development of children with Down syndrome. In D. Cicchetti\& M. Beeghly (Eds.), Children with 
Down syndrome: A developmental perspective (pp.329-368). New York: Cambridge University Press.

Benson, G., Abbeduto, L., Short, K., Bibler-Nuccio, J., \& Mass, F. (1993). Development of theory of mind in individuals with mental retardation. American Journal on Mental Retardation, 98, 427-433.

Charman, T., \& Campbell, A. (1997). Reliability of TOM task performance by individuals with a learning disability: A research note. Journal of Child Psychology and Psychiatry, 38, 725-730. http://dx.doi.org/10.1111/j.1469-7610.1997.tb01699.x

Cicchetti, D., \& Beeghly, M. (1990). Children with Down syndrome: A developmental perspective (pp.329-368). New York: Cambridge University Press. http://dx.doi.org/10.1017/CBO9780511581786

Cornish, K., Burack, J. A., Rahman, A., Munir, F., Russo, N., \& Grant, C. (2005). Theory of mind deficits in children with fragile X syndrome.Journal of Intellectual Disability Research, 49, 372-378. http://dx.doi.org/10.1111/j.1365-2788.2005.00678.x

Dunn, J. (1994). Changing minds and changing relationships. In C. Lewis \& P. Mitchell (Eds.), Children's early understanding of mind: Origins and development (pp. 297-310). Hillsdale, NJ: Erlbaum.

Dykens, E. (1998). Maladaptive behavior and dual diagnosis in persons with genetic syndromes. In J. Burack, R. Hodapp \& E. Zigler (Eds.). Handbook of mental retardation and development (pp. 542-562). Cambridge, MA: Cambridge University Press.

Dykens, E., Hodapp, R., \& Finucane, B. (2000). Genetics and Mental Retardation Syndromes: A New Look at Behavior and Interventions. Baltimore, MD: Brookes.

Dykens, E., Shah, B., Sagun, J., Beck, T., \& King, B. (2002). Maladaptive behavior in children and adolescents with Down syndrome. Journal of Intellectual Disability Research, 46, 484-492. http://dx.doi.org/10.1046/j.1365-2788.2002.00431.x

Frith, U. (1996). Social communication and its disorder in autism and Asperger syndrome. Journal of Psychopharmacology, 10, 48-53. http://dx.doi.org/10.1177/026988119601000108

Frye, D., Zelazo, P., \& Palfai, T. (1995). Theory of mind and rule-based reasoning. Cognitive Developmental, 10, 483-527. http://dx.doi.org/10.1016/0885-2014(95)90024-1

Georgas, D., Paraskevopoulos, I., Bezevegis, H., \& Giannitsas, N. (1997). Greek version of Wechsler intelligence scale for children, WISC-III. Athens: Ellinika Grammata.

Gopnick, A., \& Astington, J. (1988). Children's understanding of representational change and its relation to the understanding of false belief and the appearance-reality distinction. Child Development, 59, 26-37. http://dx.doi.org/10.2307/1130386

Gordon, A., \& Olson, D. (1998). The relation between acquisition of a theory of mind and the capacity to hold in mind. Journal of Exceptional Child Psychology, 68, 70-83. http://dx.doi.org/10.1006/jecp.1997.2423

Gottlieb, J., \& Leyser, Y. (1981). Friendship between mentally retarded children. In S.R. Asher \& J.M. Gottman (Eds.), The development of children's friendships (pp. 150-181). New York: Cambridge University Press.

Gresham, F., Elliott, S., \& Black, F. (1987). Teacher-rated social skills of mainstreamed mildly handicapped and nonhandicapped children. School Psychology Review, 16, 78-88.

Guralnick, M., Connor, R., Neville, B., \& Hammond, M. (2006). Promoting the peer related social development of young children with mild developmental delays: Effectiveness of a comprehensive intervention. American $\begin{array}{lllll}\text { Journal on } & \text { Mental } & \text { Retardation, } & \text { 336-356. }\end{array}$ http://dx.doi.org/10.1352/0895-8017(2006)111[336:PTPSDO]2.0.CO;2

Guralnick, M., Paul-Brown, D., Groom, J., Booth, C., Hammond, M., Tupper, D., \& Gelenter, A. (1998). Conflict resolution patterns of preschool children with and without developmental delays in heterogeneous playgroups. Early Education and Development, 9, 49-77. http://dx.doi.org/10.1207/s15566935eed0901_3

Hartup, W. (1999). Peer experience and its developmental significance. In M. Bennett (Ed.), Developmental psychology: Achievements and prospects (pp. 106-125). Philadelphia, PA: Psychology Press.

Hodapp, J. Burack, J., \& E. Zigler (1990). Issues in the developmental approach to mental retardation Cambridge, Mass: MIT Press. http://dx.doi.org/10.1017/CBO9780511582325.002

Hodapp, R., \& Zigler, E. (1990). Applying the developmental perspective to individuals with Down syndrome. In D. Cicchetti \& M. Beeghly, (Eds.). Children with Down syndrome: A developmental perspective (pp.1-28). New York: Cambridge University Press. http://dx.doi.org/10.1017/CBO9780511581786.002 
Hodapp, R., Burack, J., \& Zigler, E. (1990). Issues in the developmental approach to mental retardation. New York: Cambridge University Press. http://dx.doi.org/10.1017/CBO9780511582325

Hodapp, R., Burack, J., \& Zigler, E. (1990). The developmental perspective in the field of mental retardation. In R. Hodapp, J. Burack, \& E. Zigler (Eds.), Issues in the developmental approach to mental retardation (pp. 3-26). Cambridge, Mass: MIT Press.

Hogrefe, G., Wimmer, H., \& Perner, J. (1986). Ignorance versus false belief: A developmental lag in attribution of epistemic states. Child Development, 57, 567-582. http://dx.doi.org/10.2307/1130337

Howell, A., Hauser-Cram, P., \& Warfield, M. (2001). Preschool predictors of later peer acceptance and loneliness in children with disabilities. Paper presented at the biennial meeting of the Society for Research in Child Development, Minneapolis.

Hughes, C. (1998). Executive function in preschoolers: Links with theory of mind and verbalability. British Journal of Developmental Psychology, 16, 233-253. http://dx.doi.org/10.1111/j.2044-835X.1998.tb00921.x

Karmiloff-Smith, A., Klima, E., Bellugi, U., Grant, J., \& Baron-Cohen, S. (1995). Is there a social interaction module? Language, face processing, and theory-of-mind in subjects with Williams syndrome. Journal of Cognitive Neuroscience, 10, 197-208. http://dx.doi.org/10.1162/jocn.1995.7.2.196

Kasari, C., Sigman, M., Mundy, P., \& Yirmiya, N. (1990). Affective sharing in the context of joint attention interactions of normal, autistic and mentally-retarded children. Journal of Autism and Developmental Disorders, 20, 87-100. http://dx.doi.org/10.1007/BF02206859

Kavale, A., \& Forness, S. (1996). Social skill deficits and learning disabilities: A meta-analysis. Journal of Learning Disabilities, 29, 226-237. http://dx.doi.org/10.1177/002221949602900301

Leekam, S. (1991). Jokes and lies: Children's understanding of intentional falsehood. In A. Whiten (Ed.), Natural theories of mind: Evolution, development and simulation of everyday mindreading (pp.159-174). Oxford, England: Basil Blackweil.

Lewis, P., Abbeduto, L., Murphy, M., Richmond, E., Giles, N., Bruno, L., \& Schroeder, S. (2006). Cognitive, language and social-skills of individuals with fragile $\mathrm{X}$ syndrome with and without autism. Journal of Intellectual Disability Research, 50, 532-545. http://dx.doi.org/10.1111/j.1365-2788.2006.00803.x

Luckasson, R., Borthwick-Duffy, S., Buntinx, W., Coulter, D., Craig, E., Reeve, A., Schalock, R., Snell, M., Spitalnik, D., Spreat, D., \& Tasse, M. (2002). Mental Retardation: Definition, Classification and Systems of Supports ( $10^{\text {th }}$ ed.). Washington, DC: American Association on Mental Retardation.

MacLean, W. (1997). Ellis' handbook of mental deficiency, psychological theory and research (3rd ed.). Mahwah, NJ: Erlbaum.

Margalit, M. (1995). Effects of social skills training for students with an intellectual disability. International Journal of Disability, Development and Education, 42, 75-85. http://dx.doi.org/10.1080/0156655950420108

Mazzocco, M., Pennington, B., \& Hagerman, R. (1993). The neurocognitive phenotype of female carriers of fragile X: further evidence for specificity. Journal of Developmental and Behavioral Pediatrics, 14, 328-335. http://dx.doi.org/10.1097/00004703-199310000-00007

Nadel, L. (2006). Neuropsychological aspects of Down syndrome. In J.A. Rondal \& J. Perrera (Eds.), Down syndrome: Neurobehavioral specificity (pp. 67-85). London, UK: John Wiley and sons.

Pennington, B., \& Ozonoff, S. (1996). Executive functions and developmental psychopathology. Journal of Child Psychology and Psychiatry, 37, 51-87. http://dx.doi.org/10.1111/j.1469-7610.1996.tb01380.x

Perner, J., \& Howes, D. (1992). "He thinks he knows": And more developmental evidence against simulation (role-taking) theory. Mind and Language, 7, 72-86. http://dx.doi.org/10.1111/j.1468-0017.1992.tb00197.x

Perner, J., \& Wimmer, H. (1985). John thinks that Mary thinks that 1: Attribution of second-order beliefs by 5-to 10 year-old children. Journal of Experimental Child Psychology, 39, 437-471. http://dx.doi.org/10.1016/0022-0965(85)90051-7

Rondal, J. (1996). Oral language in Down syndrome. In J. Rondal, J. Perera, L. Nadel, \& A. Comblain (Eds.). Down's syndrome: Psychological, psychobiological, and socio-educational perspectives (pp. 99-117). London: Whurr.

Simonoff, E., Bolton, P., \& Rutter, M. (1996). Mental retardation: Genetic findings, clinicalimplications and research agenda. Journal of Child Psychology and Psychiatry, 37, 259-280. 
http://dx.doi.org/10.1111/j.1469-7610.1996.tb01404.x

Sullivan, K., \& Tager-Flusberg, H. (1999). Second-order belief attribution in Williams Syndrome: Intact or impaired? American Journal on Mental Retardation, 6, 523-532. http://dx.doi.org/10.1352/0895-8017(1999)104<0523:SBAIWS>2.0.CO;2

Sullivan, K., Zaitchik, D., \& Tager-Plusberg, H. (1994). Preschoolers can attribute second-order beliefs. Developmental Psychology, 30, 395-402. http://dx.doi.org/10.1037/0012-1649.30.3.395

Tager-Flusberg, H., \& Sullivan, K. (1994) Predicting and explaining behavior: A comparison of autistic, mentally retarded and normal children. Journal of Child Psychology and Psychiatry, 35, 1059-1075. http://dx.doi.org/10.1111/j.1469-7610.1994.tb01809.x

Williams, G., \& Asher, S. (1992). Assessment of loneliness at school among children with mild mental retardation.American Journal on Mental Retardation, 96, 373-385.

Yirmiya, N., Erel, O., Shaked, M., \& Solomonica-Levi, D. (1998). Meta-analyses comparing theory of mind abilities in individual with autism, individuals with mental retardation, and normally developing individuals, Psychological Bulletin, 124, 283-305. http://dx.doi.org/10.1037/0033-2909.124.3.283

Zelazo, P., Burack, J., Benedetto, E., \& Frye, D. (1996). Theory of mind and rule use in individuals with Down syndrome: A test of the uniqueness and specificity claims. Journal of Child Psychology and Psychiatry, 37, 479-484. http://dx.doi.org/10.1111/j.1469-7610.1996.tb01429.x

Zigler, E. (1969).Developmental versus difference theories of mental retardation and the problem of motivation, American Journal of Mental Deficiency, 73, 536-556.

Table 1. Mean scores and standard deviations on false beliefs tasks by group

\begin{tabular}{|l|l|l|l|}
\hline Group & $\mathbf{N}$ & Mean & $\begin{array}{l}\text { Standard } \\
\text { Deviations }\end{array}$ \\
\hline ID & 41 & 2.93 & 1.36 \\
\hline DS & 23 & 1,17 & 0.83 \\
\hline TD & 42 & 4 & 1.23 \\
\hline Total & 106 & 2.97 & 1.6 \\
\hline
\end{tabular}

The scores in the result section are out of 5 . 